\title{
Autoimmune pulmonary alveolar proteinosis developed during immunosuppressive treatment in polymyositis with interstitial lung disease: a case report
}

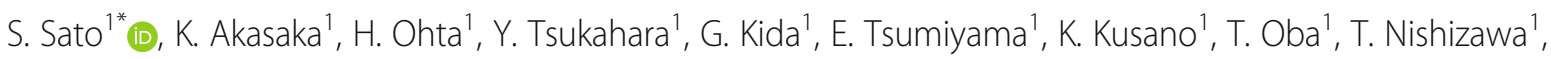

R. Kawabe', H. Yamakawa', M. Amano' ', H. Matsushima' and T. Takada ${ }^{2}$

\begin{abstract}
Background: Pulmonary alveolar proteinosis (PAP) is characterized by the accumulation of surfactant proteins within the alveolar spaces. Autoimmune PAP (APAP) caused by elevated levels of GM-CSF autoantibodies (GM-Ab) is very rarely associated with systemic autoimmune disease. Here we report a case of APAP manifested during immunosuppressive treatment for polymyositis with interstitial lung disease.

Case presentation: A 52-year-old woman treated at our hospital because of polymyositis with interstitial pneumonia had maintained remission by immunosuppressive treatment for 15 years. She had progressive dyspnea subsequently over several months with her chest CT showing ground-glass opacities (GGO) in bilateral geographic distribution. Her bronchoalveolar lavage fluid with cloudy appearance revealed medium-sized foamy macrophages and PAS-positive amorphous eosinophilic materials by cytological examination. We diagnosed her as APAP due to an increased serum GM-CSF autoantibody level. Attenuating immunosuppression failed to lead GGO improvement, but whole lung lavage (WLL) was effective in her condition.
\end{abstract}

Conclusions: PAP should be considered as one of the differential diseases when the newly interstitial shadow was observed during immunosuppressive treatment. WLL should be regarded as the treatment option for APAP concurred in connective tissue disease (CTD).

Keywords: Pulmonary alveolar proteinosis, Polymyositis, GM-CSF, Immunosuppressive treatment

* Correspondence: smallerss@hotmail.com

'Department of Respiratory Medicine, Saitama Red Cross Hospital, 1-5,

Shintoshin, Chuo-ku, Saitama 330-8553, Japan

Full list of author information is available at the end of the article

(c) The Author(s). 2020 Open Access This article is licensed under a Creative Commons Attribution 4.0 International License, which permits use, sharing, adaptation, distribution and reproduction in any medium or format, as long as you give appropriate credit to the original author(s) and the source, provide a link to the Creative Commons licence, and indicate if changes were made. The images or other third party material in this article are included in the article's Creative Commons licence, unless indicated otherwise in a credit line to the material. If material is not included in the article's Creative Commons licence and your intended use is not permitted by statutory regulation or exceeds the permitted use, you will need to obtain permission directly from the copyright holder. To view a copy of this licence, visit http://creativecommons.org/licenses/by/4.0/ The Creative Commons Public Domain Dedication waiver (http://creativecommons.org/publicdomain/zero/1.0/) applies to the data made available in this article, unless otherwise stated in a credit line to the data. 


\section{Background}

Pulmonary alveolar proteinosis (PAP) is a rare syndrome resulting from the accumulation of lipoproteinaceous materials in the alveoli and terminal airways due to impairment of surfactant clearance by alveolar macrophage [1]. PAP can be classified into several types based on the pathogenesis [2]. Primary PAP is characterized by the disruption of granulocyte-macrophage colony-stimulating factor (GMCSF) signalling pathway: autoimmune (caused by elevated levels of GM-CSF autoantibodies) or hereditary (due to mutations in encoding GM-CSF receptor subunits). Secondary PAP results from various underlying diseases. Congenital PAP is caused by mutations in genes involved in surfactant production. Interestingly, autoimmune PAP (APAP) is very rarely associated with systemic autoimmune disease. Only a few cases can be found in registry studies and case reports [3-9]. Furthermore, APAP complicated with dermatomyositis/polymyositis was reported only in one case of aminoacyl-tRNA synthetases (ARS) related dermatomyositis [7]. Here we report a case of APAP manifested during long-term immunosuppressive treatment for polymyositis with interstitial lung disease.

\section{Case presentation}

A 52-year-old Japanese woman visited our hospital in 2004 with complaints of dyspnea, dry cough, and myalgia. She had signs of myalgia and muscle weakness of the upper limbs, increased serum creatine kinase (1315 $\mathrm{IU} / \mathrm{L})$, and fibrillation potential and short duration neuromuscular unit (NMU) in electromyogram. We diagnosed her as polymyositis based on the diagnostic criteria of the Ministry of Health, Labour and Welfare's Autoimmune Disease Research Group of Japan. No skin symptoms were observed. Chest CT findings revealed reticular shadows and ground-glass opacities (GGOs) in bilateral lower lobes peripherally from around the bronchovascular bundle. The bronchoalveolar lavage fluid (BALF) with transparent appearance contained $2.4 \times 10^{5}$ cells $/ \mathrm{mL}, 44.6 \%$ macrophages, $52.2 \%$ lymphocytes, $1.8 \%$ neutrophils, and $1.4 \%$ eosinophils. Lymphocytes increment was observed but no findings suggesting PAP on cytology. Microbiological tests for bacteria, fungi, or acid-fast bacilli in BALF were also negative. The titer of GM-Ab was not measured.

She was diagnosed as polymyositis with interstitial pneumonia. Corticosteroid therapy (prednisolone; $40 \mathrm{mg} /$ day) immediately improved both myalgia and dyspnea. Serum creatine kinase and KL-6 levels also decreased to normal ranges. As for CT findings, the reticular opacities and GGOs diminished. We gradually tapered prednisolone doses and her medical condition had been wellcontrolled by immunosuppressive treatment over 15 years since the diagnosis (Figs. 1, 2A).

In early 2019, she visited our hospital because of progressive dyspnea and slight productive cough for 4 months under treatment with prednisolone $7.5 \mathrm{mg}$ /day (Fig. 1). Chest auscultation revealed fine crackles on inspiration in the bibasilar area. The physical examination revealed no skin lesions such as sclerosis, Gottron's sign, heliotrope rash, mechanic's hands, or Raynaud's phenomenon, and

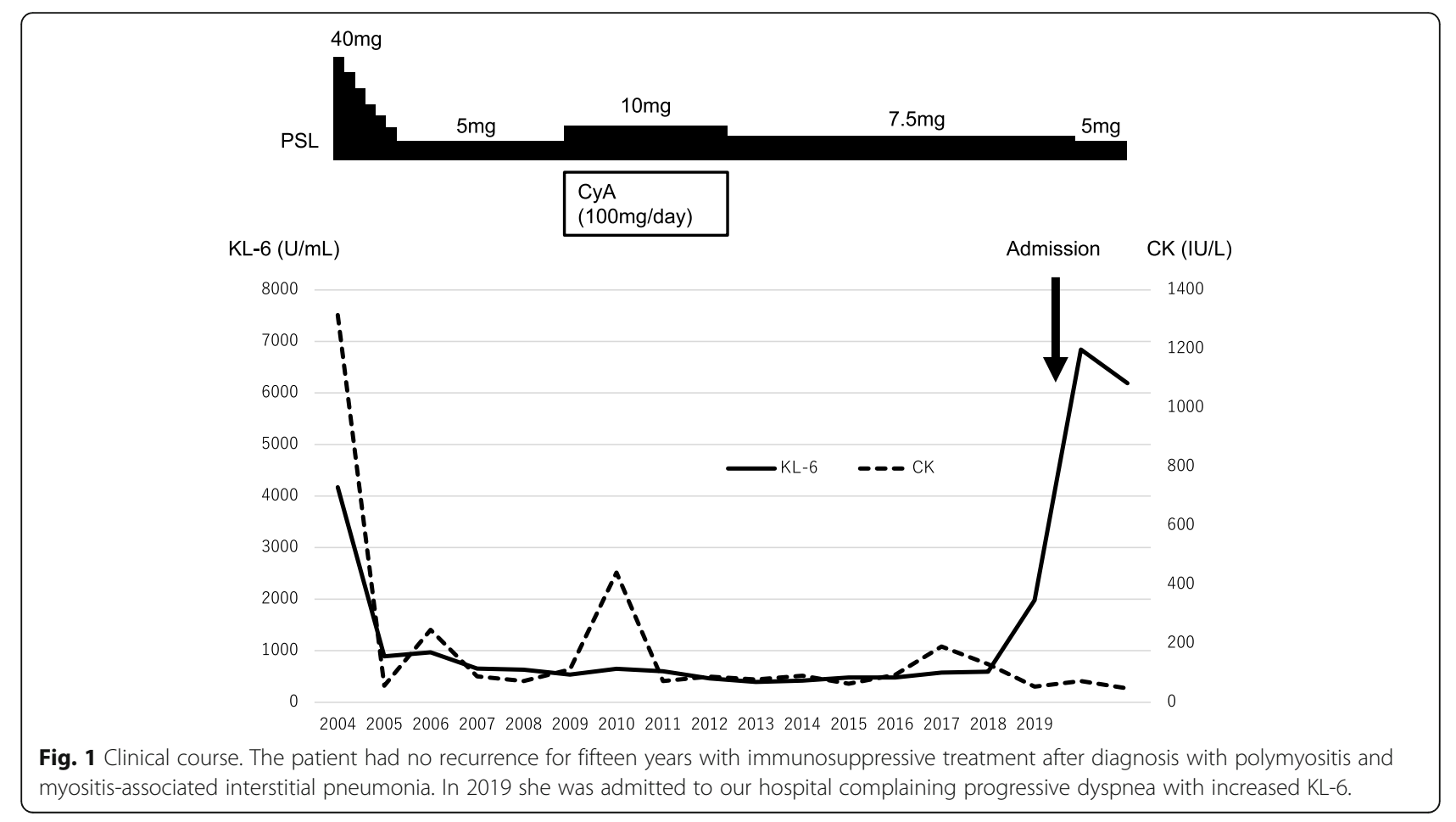




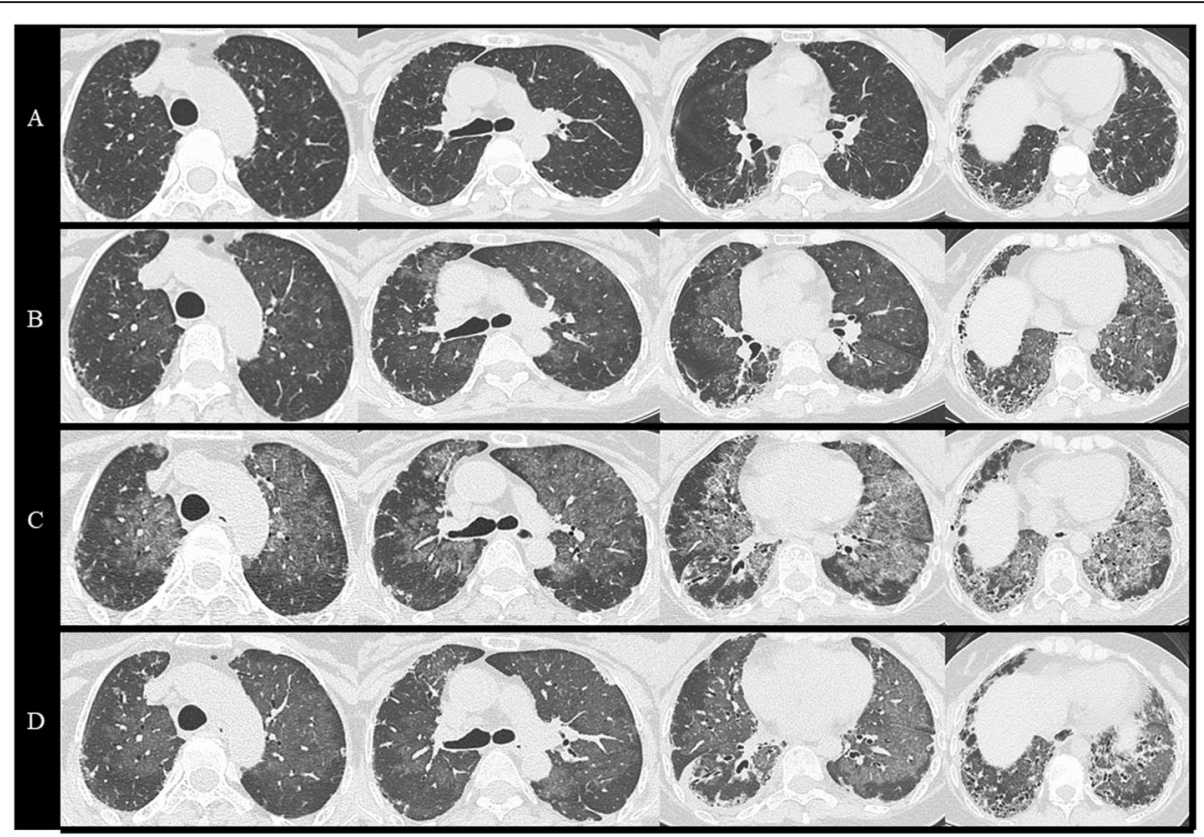

Fig. 2 Chest CT findings. A Four months before admission, her chest CT showed a subpleural and basal predominant reticular pattern with peripheral traction bronchiectasis. B On admission, extensive GGOs with geographic distribution appeared bilaterally. C Immediately before WLL, GGOs worsened further in both lung fields four months after the diagnosis. D After WLL, GGOs improved significantly with no change in the underlying interstitial pneumonia.

no myalgia, muscle atrophy, or arthralgia. Chest CT showed subpleural reticular opacities predominantly in the lower lobes accompanying contraction and extensive GGOs in geographic distribution (Fig. 2B).

Laboratory examinations revealed significantly high serum levels of KL-6 (6843 U/mL) and SP-D (362 ng/ $\mathrm{mL})$. The serum creatine kinase $(72 \mathrm{IU} / \mathrm{L})$, aldolase $(5.3$ $\mathrm{IU} / \mathrm{L})$, and C-reactive protein levels $(0.27 \mathrm{mg} / \mathrm{dL})$ were within the normal range. The serum anti-ARS antibody level was positive at 115 index, whereas anti-melanoma differentiation-associated gene 5 (MDA-5) antibody level was negative. RNA immunoprecipitation assay indicated the positivity of anti-SS-A/Ro52 and anti-EJ, one of the anti-ARS antibodies. An arterial blood gas analysis showed decreased partial pressure of oxygen $\left(\mathrm{PaO}_{2}\right)$ (74.5 Torr) with elevated alveolar-arterial oxygen gradient $\left(\mathrm{A}-\mathrm{aDO}_{2}\right)$ (22.3 Torr). The respiratory function tests showed severely impaired forced vital capacity (FVC) of $0.6 \mathrm{~L}$ (28.5\%, \%predicted) and forced expiratory volume in $1 \mathrm{~s}$ (FEV1) of $0.69 \mathrm{~L}$ (35.2\%, \% predicted) with $100.0 \%$ of FEV1/FVC ratio. The diffusing capacity of carbon monoxide $\left(\mathrm{DL}_{\mathrm{CO}}\right)$ could not evaluate due to low FVC.

The BALF with cloudy appearance contained $3.7 \times 10^{5}$ cells $/ \mathrm{mL}$ consisting of $85.2 \%$ macrophages, $9.6 \%$ lymphocytes, $3.6 \%$ neutrophils, and $1.4 \%$ eosinophils. Microbiological tests, including Pneumocystis jirovecii polymerase chain reaction (PCR) in BALF, were negative. A cytological examination of BALF revealed medium-sized foamy macrophages with acellular periodic acid-Schiff (PAS) positive bodies. Transbronchial lung biopsy specimens showed myxoid-appearing organization in alveolar space and alveolar duct, but no amorphous PAS-positive materials. Because these pathological findings strongly suggested PAP, we measured serum GM-CSF autoantibody (GM-Ab) levels and found positive at $80.1 \mu \mathrm{g} / \mathrm{mL}$ (cut off value $<1.0 \mu \mathrm{g} / \mathrm{mL}$ ) $[10,11]$. Based on these results, we diagnosed her as APAP in myositis with interstitial pneumonia with severity 2 according to the disease severity score (DSS) [3].

According to the previous report [7] prednisolone dose was decreased from $7.5 \mathrm{mg} /$ day to $5.0 \mathrm{mg} /$ day. However, in a gradual progression of her chest imaging findings (Fig. 2C), we performed whole lung lavage (WLL) 4 months after the diagnosis of APAP. The washed-out recovery fluid revealed milky appearance typical of PAP with sediment. It contained foamy macrophages with a background of eosinophilic proteinaceous granular materials (Fig. 3). After the treatment, the GGOs in both lung fields were remarkably improved on CT (Fig. 2D). We found no obvious recurrence of myositis, interstitial pneumonia, or PAP for the following several months.

\section{Discussion and conclusions}

We experienced a case of APAP complicated with polymyositis accompanying interstitial lung disease. As the interstitial lung abnormality confirmed at first visit day, 


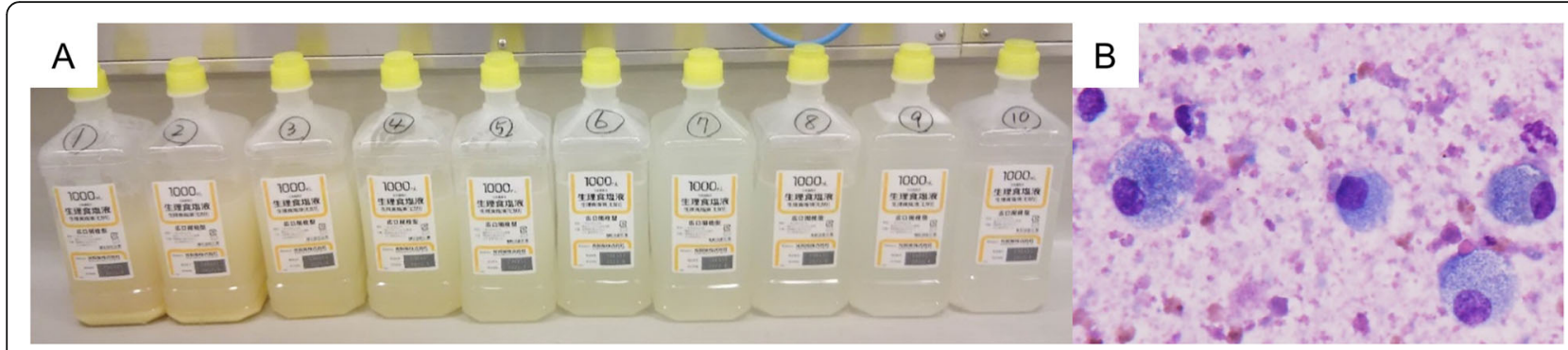

Fig. 3 Washed-out recovery fluid of WLL. A Gross findings showed a milky appearance with sediment. B Microscopic results revealed foamy macrophages backed by eosinophilic proteinaceous granular materials

we considered it to be the myositis-related interstitial pneumonia. The disorder revealed no cloudy appearance of BALF with no pathological findings suggesting PAP, and resolved with immunosuppressive treatment including corticosteroid. We previously reported that corticosteroid therapy might exacerbate APAP [12]. Thus, although the GM-Ab titer was not measured, it is unlikely that the patient had a mild form of APAP when diagnosed as polymyositis with interstitial pneumonia. The patient developed APAP during the immunosuppressive treatment for polymyositis for 15 years. Attenuation of the immunosuppression did not affect newly appeared GGO, but whole lung lavage (WLL) remarkably improved her $\mathrm{CT}$ findings and respiratory condition.

There are very few cases of PAP complicated with connective tissue disease (CTD). Seymour reported only 7 out of 410 PAP cases (1.7\%) diagnosed within the period from 1958 to 2002 [1]. According to a report from the Japanese registry, CTD was only found in 3 out of 223 cases of APAP $(1.3 \%, 1999-2006)$ [3]. We confirmed six cases with CTD complicated with APAP from 1998 to 2019 by searching in the PubMed website (Table 1) [5-9]. All cases were treated by immunosuppressive agents.

Several case reports showed improved CT findings with only corticosteroid reduction [5-7]. We hypothesize that immunosuppressive treatment with corticosteroid might cause alveolar macrophage dysfunction and increase the accumulation of phospholipids in the alveolar air space. Then it is plausible that the use of immunosuppressive agents could promote the development of potential PAP [12-15] and that corticosteroid reduction caused improvement of CT findings.

GM-CSF regulates the clearance of surfactant by alveolar macrophages. GM-Ab, antibodies to GM-CSF neutralize the effect of GM-CSF on alveolar macrophages, resulting in the maturation arrest of those cells and the development of PAP. GM-Ab in APAP only consisted of the IgG isotype [11]. Immunosuppressive drugs with corticosteroids usually decrease the serum level of IgG. Some patients, however, develop APAP under treatment, which implies that IgG of GM-Ab may be produced independently in immunosuppressive therapy.

The 6 cases listed on the Table 1 can be divided into two groups. The first group (Case 1-3) developed APAP in 2 months to 3.5 years during an intensive immunosuppressive treatment and improved by tapering the therapy without WLL. Whereas the other group with our case (Case 4-7) developed APAP in 5 to 26 years during mild immunosuppressive treatment and required WLL. This long-term group showed more elevated GM$\mathrm{Ab}$ levels than the short-term group. GM-Ab was likely produced by continuous GM-CSF stimulation in the

Table 1 Previously reported cases with autoimmune PAP complicated with CTDs

\begin{tabular}{|c|c|c|c|c|c|c|c|c|c|c|}
\hline Case & Author & Age & Sex & Duration & $\begin{array}{l}\text { Time to } \\
\text { onset }\end{array}$ & $\begin{array}{l}\text { CTD } \\
\text { precedence }\end{array}$ & CTD & $\begin{array}{l}\text { GM-Ab } \\
(\mu \mathrm{g} / \mathrm{mL})\end{array}$ & $\begin{array}{l}\text { Regular } \\
\text { Treatment }\end{array}$ & $\begin{array}{l}\text { PAP } \\
\text { Treatment }\end{array}$ \\
\hline $1[5]$ & Nagasawa & 26 & $\mathrm{~F}$ & month to year & $2 \mathrm{M}$ & Yes & SLE & 10.6 & $P S L+I V C Y$ & reduce PSL + discontinue IVCY \\
\hline $2[6]$ & Yamasue & 64 & $\mathrm{~F}$ & & $1.1 Y$ & Yes & SSC & 10.8 & $P S L+I V C Y$ & reduce PSL + discontinue TAC \\
\hline 3 [7] & Imura & 58 & $\mathrm{~F}$ & & $3.5 \mathrm{Y}$ & Yes & DM & 1.8 & PSL + CyA & reduce PSL \\
\hline $4[8]$ & Ito & 65 & $\mathrm{~F}$ & year to decade & $5 Y$ & Yes & RA & 26.1 & MTX + SASP & WLL + inhalation GM-CSF \\
\hline 5 & Our case & 52 & $\mathrm{~F}$ & & $15 Y$ & Yes & PM & 80.1 & PSL & reduce PSL + WLL \\
\hline $6[9]$ & Sakamoto & 65 & M & & $20 Y$ & Yes & $U C$ & 62.8 & SASP & WLL \\
\hline 7 [8] & Ito & 68 & $\mathrm{~F}$ & & $26 Y$ & Yes & RA & 42.3 & SASP & WLL + inhalation GM-CSF \\
\hline
\end{tabular}

CTD connective tissue disease, CyA cyclosporine A, DM dermatomyositis, GM-Ab granulocyte-macrophage colony-stimulating factor autoantibody, GM-CSF granulocyte-macrophage colony-stimulating factor, IVCY intravenous cyclophosphamide, MTX methotrexate, RA rheumatoid arthritis, SASP salazosulfapyridin, SLE systemic lupus erythematosus, SSC systemic sclerosis, TAC tacrolimus, UC ulcerative colitis, WLL whole lung lavage 
long-term remedy for CTD. These results suggest that immunoinflammatory pathology for the development of APAP might be different between these groups.

Physicians rarely consider PAP as a diagnosis when they found unanticipated interstitial opacity during the treatment course of CTDs. Most probable differential diagnoses are as follows: opportunistic infection including Pneumocystis jirovecii or CMV pneumonia, a progression of CTD-related interstitial pneumonia, and drug-induced lung injury. None of these differential disorders was likely in this case because of no positive microbiological tests of BALF, no exacerbation of CTD, and no newly administered drugs. Kitamura recently reported, however, that APAP occurs more frequently than previous reports [16], which suggests that PAP cases might be overlooked among CTD cases treated with immunosuppressive agents.

Recently, a high incidence of juvenile idiopathic arthritis-associated lung disease is reported [17]. Eighteen patients with the disease showed a pulmonary histopathology pattern of endogenous lipoid pneumonia and PAP without GM-Ab. The heritability of APAP has not been proven and is considered to be unrelated to HLA [18]. PAP may be more likely to occur in CTD with or without the GM-Ab. One reason is that we suspect that immunosuppressive drugs could manifest APAP by macrophage dysfunction or opportunistic infection. We may need to be more cautious with CTDs that potentially coexists with PAP [18].

In the present case, we performed WLL with no significant complications. However, it was also a great concern about postoperative pneumonia, respiratory failure, and acute exacerbation of interstitial pneumonia. In the cases of refractory PAP, rituximab and plasmapheresis were also reported as treatment options $[19,20]$. Recently, Tazawa et al. reported that inhaled recombinant human GM-CSF was associated with a modest salutary effect on the laboratory outcome of arterial oxygen tension in a randomized, controlled trial [21]. The efficacy and safety of recombinant human GM-CSF for the PAP with pulmonary fibrosis should be studied.

In conclusion, we experienced a case of APAP associated with polymyositis and myositis-related interstitial pneumonia. This rare concurrence might not a coincidence because of previous reports. Among CTD cases treated with immunosuppressive agents, PAP should be considered as one of the differential diagnosis when unexpected interstitial opacities were observed. WLL is useful as a standard treatment for those cases.

\section{Abbreviations}

APAP: Autoimmune pulmonary alveolar proteinosis; ARS: Aminoacyl-tRNA synthetase; BALF: Bronchoalveolar lavage fluid; CK: Creatine kinase; CTD: Connective tissue disease; CyA: Cyclosporine A; GGO: Ground-glass opacity; GM-Ab: GM-CSF autoantibody; GM-CSF: Granulocyte-macrophage colony-stimulating factor; KL-6: Krebs von den lungen-6; PAP: Pulmonary alveolar proteinosis; WLL: Whole lung lavage

\section{Acknowledgments}

We would like to thank Koh Nakata, Niigata University, for grateful discussions. Also, Yuko Itoh, Niigata University, for measuring serum GM-Ab levels. We appreciate Jiro Kamiyama, Toshiya Tomioka, and other members who joined the medical team for the treatment.

\section{Authors' contributions}

$\mathrm{SS}$ and $\mathrm{AK}$ were involved in the acquisition of the data; SS, AK, OH, TY, KG, $\mathrm{TE}, \mathrm{KK}, \mathrm{OT}, \mathrm{NT}, \mathrm{KR}, \mathrm{YH}, \mathrm{AM}, \mathrm{MH}$ and $\mathrm{TT}$ were involved in the analysis and interpretation of the clinical data; and SS and AK were involved in the drafting of the manuscript. All authors read and approved the final manuscript.

\section{Funding}

This work was supported by a grant of Grants-in-Aid for Scientific Research, Grant Number JP16K09530 (AK), from Japan Society for the Promotion of Science (JSPS) to measure GM-CSF autoantibody.

Availability of data and materials

All the data regarding the findings are available within the manuscript.

Ethics approval and consent to participate

Not applicable.

\section{Consent for publication}

Written, informed consent was obtained from the patient for publication of this case report and any accompanying images. A copy of the written consent is available for review by the editor of this journal.

\section{Competing interests}

The authors declare that they have no competing interests.

\section{Author details}

${ }^{1}$ Department of Respiratory Medicine, Saitama Red Cross Hospital, 1-5, Shintoshin, Chuo-ku, Saitama 330-8553, Japan. ²Uonuma Institute of Community Medicine, Niigata University Medical and Dental Hospital, Minami-Uonuma, Japan.

Received: 19 January 2020 Accepted: 10 March 2020

Published online: 06 April 2020

References

1. Seymour JF, Presneill JJ. Pulmonary alveolar proteinosis: progress in the first 44 years. Am J Respir Crit Care Med. 2002;166:215-35.

2. Trapnell BC, Nakata K, Bonella F, Campo I, Griese M, Hamilton J, et al. Pulmonary alveolar proteinosis. Nat Rev Dis Primers. 2019;5:16.

3. Ishii H, Tazawa R, Kaneko C, Saraya T, Inoue Y, Hamano E, et al. Clinical features of secondary pulmonary alveolar proteinosis: premortem cases in Japan. Eur Respir J. 2011;37:465-8.

4. Inoue Y, Trapnell BC, Tazawa R, Arai T, Takada T, Hizawa N, et al. Characteristics of a large cohort of patients with autoimmune pulmonary alveolar proteinosis in Japan. Am J Respir Crit Care Med. 2008;177:752-62.

5. Nagasawa J, Kurasawa K, Maezawa R, Owada T, Hanaoka R, Fukuda T. Systemic lupus erythematosus complicating autoimmune pulmonary alveolar proteinosis that was worsened by immunosuppressive therapy. Lupus. 2013;22:1060-3

6. Yamasue M, Nureki SI, Usagawa Y, Ono T, Matsumoto H, Kan T, et al. Elevated serum anti-GM-CSF antibodies before the onset of autoimmune pulmonary alveolar Proteinosis in a patient with Sarcoidosis and systemic sclerosis. Tohoku J Exp Med. 2017;243:77-83.

7. Imura Y, Yukawa N, Handa T, Nakashima R, Murakami K, Yoshifuji H, et al. Two cases of autoimmune and secondary pulmonary alveolar proteinosis during imunosuppressive therapy in dermatomyositis with interstitial lung disease. Mod Rheumatol. 2018:28:724-9.

8. Ito S, Wakahara K, Kojima T, Takahashi N, Nishiwaki K, Yamaguchi E, et al. Two cases of autoimmune pulmonary alveolar proteinosis with rheumatoid arthritis. Allergol Int. 2017;66:507-9. 
9. Sakamoto N, Nakashima S, Ishimoto H, Kakugawa T, Hara A, Yura H, et al. Pulmonary alveolar Proteinosis with ulcerative colitis. Intern Med. 2018;57: 2705-8.

10. Uchida K, Nakata K, Carey B, Chalk C, Suzuki T, et al. Standardized serum GM-CSF autoantibody testing for the routine clinical diagnosis of autoimmune pulmonary alveolar proteinosis. J Immunol Methods. 2014;402: $57-70$.

11. Kitamura T, Uchida K, Tanaka N, Tsuchiya T, Watanabe J, Yamada Y, et al. Serological diagnosis of idiopathic pulmonary alveolar proteinosis. Am J Respir Crit Care Med. 2000;162:658-62.

12. Akasaka K, Tanaka T, Kitamura N, Ohkouchi S, Tazawa R, Takeda T, et al. Outcome of corticosteroid administration in autoimmune pulmonary alveolar proteinosis: a retrospective cohort study. BMC Pulm Med. 2015;15: 88.

13. Wilson DO, Rogers RM. Prolonged spontaneous remission in a patient with untreated pulmonary alveolar proteinosis. Am J Med. 1987;82:1014-6.

14. Rinehart JJ, Sagone AL, Balcerzak SP, Ackerman GA, LoBuglio AF. Effects of corticosteroid therapy on human monocyte function. N Engl J Med. 1975; 292:236-41

15. Linden M, Brattsand R. Effects of a corticosteroid, budesonide, on alveolar macrophage and blood monocyte secretion of cytokines: differential sensitivity of GM-CSF, IL-1 beta, and IL-6. Pulm Pharmacol. 1994;7:43-7.

16. Kitamura N, Ohkouchi S, Tazawa R, Ishii H, Takada T, Sakagami T, et al. Incidence of autoimmune pulmonary alveolar proteinosis estimated using Poisson distribution. ERJ Open Res. 2019. https://doi.org/10.1183/23120541.

17. Schulert GS, Yasin S, Carey B, Chalk C, Do T, et al. Systemic juvenile idiopathic arthritis-associated lung disease: characterization and risk factors. Arthritis Rheumatol. 2019;71:1943-54.

18. Anderson K, Carey B, Martin A, Roark C, Chalk C, et al. Pulmonary alveolar proteinosis: an autoimmune disease lacking an HLA association. PLoS One. 2019;14:e0213179. https://doi.org/10.1371/journal.pone.0213179.

19. Kavuru MS, Malur A, Marshall I, Barna BP, Meziane M, Huizar I, et al. An open-label trial of rituximab therapy in pulmonary alveolar proteinosis. Eur Respir J. 2011;38:1361-7.

20. Garber B, Albores J, Wang T, Neville TH. A plasmapheresis protocol for refractory pulmonary alveolar proteinosis. Lung. 2015;193:209-11.

21. Tazawa R, Ueda T, Abe M, Tasumi K, Eda R, Kondoh S, et al. Inhaled GM-CSF for Pulmonary Alveolar Proteinosis. N Engl J Med. 2019;381:923-32.

\section{Publisher's Note}

Springer Nature remains neutral with regard to jurisdictional claims in published maps and institutional affiliations.

Ready to submit your research? Choose BMC and benefit from:

- fast, convenient online submission

- thorough peer review by experienced researchers in your field

- rapid publication on acceptance

- support for research data, including large and complex data types

- gold Open Access which fosters wider collaboration and increased citations

- maximum visibility for your research: over $100 \mathrm{M}$ website views per year

At $\mathrm{BMC}$, research is always in progress.

Learn more biomedcentral.com/submissions 